\title{
Title: Get Up, Stand Up: A Brief History of Sedentarism and Why Movement is Good Medicine
}

\author{
Key words: Back Pain, Ergonomics, Sedentary, Obesity, Posture
}

Sedentary behaviors, like watching TV, have been have been linked to an increased risk of all-cause and cardiovascular disease mortality independent of other risk factors such as smoking, high blood pressure, cholesterol, diet, and waist circumference [1]. While it is unknown how much actual sedentary time most Americans accrue throughout the day, it is known that sedentary behavior makes up most of our self-reported leisure time, with television watching alone accounting for $50 \%$ of our daily 5.3 hours of leisure time [2]. In my talk, I first address the question: Why are people of today more sedentary than those of previous generations? Next, I explore how being sedentary affects our health and how TV watching alone has been correlated with increased risk of disease and death. I then discuss the invention of the chair and when we started sitting as a species. I close the discussion with evidence showing that "movement breaks" can be an effective countermeasure to prolonged sitting and how technology is now being used help us to become more active rather than less.

\section{Why are people of today more sedentary than those of previous generations?}

In 190041 percent of the United States workforce was employed in agriculture. By 1930 that number had dropped to 21.5 percent, in 1945 it was 16 percent, in 1970 it was 4 percent, and today, it's less than 2 percent [3]. Farm jobs are notoriously physical and as greater and greater numbers of people left the farm and field to find work in urban settings, vigorous, active time was traded for sedentary work. Other types of labor intensive jobs, such as manufacturing, have seen declines as well and physically active jobs now make up less than $20 \%$ of occupations while sedentary work has increased $83 \%$ since 1950 [4]. The net effect of this shift in work-related physical activity is that both men and women, on average, expend 100 calories less per day than they would have 50 years ago [5].

As the nature of work has changed, so too has the educational system. While schools once provided ample opportunities to develop young bodies as well as young minds, the emphasis is increasingly being placed on mental tasks. The increasing role of standardized testing has amplified this trend as educational budgets are now tied to specific measures of academic performance. Resources that were once allocated for school-day physical education are being cut, and in a recent survey of school administrators, $44 \%$ report significant reductions in time spent in physical education, art, music, and recess in order to focus on test subjects such as reading and mathematics [6].

Technological advances have also played a role in reducing our physical activity, and it's not just through labor-saving effects in the workplace. Recreational leisure time for both kids and adults used to revolve around sports, games, dancing, playing music, and other physical activities but it is now being displaced by sedentary activities like watching TV, browsing websites on a computer or smart phone, or playing video games. In a 2003-2004 survey of 6,329 people across a representative sample of the U.S. population, it was found that participants spent an average of 7.7 hours a day engaged in sedentary behaviors [7]. This survey employed activity monitors instead of relying on self-reported assessments of 
specific sedentary activities and showed that previous attempts to quantify sedentary time likely underestimated real-world behavior.

\section{What are the health effects of being sedentary?}

The phrase "sitting is the new smoking" has recently emerged in the cultural lexicon as a way to describe the real health threat prolonged sitting presents. Even in people who regularly exercise, sedentary activities like watching TV contribute to the development of cardiovascular disease, blood sugar regulation disorders like type 2 diabetes, and even cancer risk [8]. In an Australian study, it was found that there was an $11 \%-18 \%$ increase in risk for all-cause and cardiovascular disease mortality with each additional hour of TV watched and relative to people who watched less than two hours of TV a day, people who watched more than four hours a day had a $46 \%$ increased risk of all-cause and an $80 \%$ increased risk of cardiovascular disease mortality [9].

Prolonged sitting is also a known risk factor for the development of low back pain a condition which has a lifetime incidence rate of 50-90\% [10]. Sitting contributes to the development of low back pain by increasing pressure in the intervertebral discs which separate the vertebrae of the lumbar spine, and when back pain becomes chronic, it can also lead to increased obesity and morbidity risk [11].

\section{When did we start sitting as a species?}

Although squatting on the ground is common in great apes, monkeys, human hunter gatherers, and modern cultures like that of India and Japan, sitting in chairs predominates in many countries including the U.S. It's thought that the ancient Egyptians were the first society to manufacture and use stools and chairs (stools with backs), but these early chairs were reserved for use primarily by high status individuals. This practice, reserving seating for nobility, continued through the Greek and Roman times as well as the Middle Ages [12] [13].

18th century chair makers, Thomas Chippendale and Michael Thonet, sometimes referred to as the "Henry Ford of chairs," ushered in the modern era of chair design and mass manufacture [14]. With mass production came reduced prices and for the first time in human history, just about anyone could afford a chair. Through the 19th century materials innovations, like the use of plastics, fueled an explosion in chair design innovation and consumers adopted chairs into nearly all aspects of their lives.

\section{Combating sedentarism with movement and technology.}

Due to the ever present threat of famine during much of our evolutionary history, it is thought that humans possess a number of "thrifty" genes which influence traits like the propensity to gain fat, the tendency to gorge oneself, and laziness (i.e. energy conservation) [15]. At the time these traits were selected for it was advantageous to be able to easily put on weight, and keep it on, despite fluctuating food availability. It is only now, in our modern environment of plentiful easily available food, that our genes have become maladaptive. 
The human body is capable performing thousands of different movements in almost unlimited combinations, but for the average American, their movement "diet" is limited to a handful of repetitive, evolutionarily novel, and mostly sedentary patterns like watching TV, playing video games, or browsing the internet on a computer. In the words of biomechanist and author Katy Bowman, many of us are lacking "nutritious movement" in much of the same way that the Standard American Diet of fast food and processed treats is lacking in vitamins and minerals [16].

Thanks to our thrifty genes, sedentary behaviors also carry the same built-in appeal as processed food and as labor-saving and entertainment technology has developed, we have had more and more opportunities to indulge our hunger for comfort and ease. Thankfully however, we are now seeing technological solutions to the sedentarism problem. Companies like Fitbit and Apple are building functional and stylish wearable activity trackers which can be set to provide movement reminders. On the software side, apps like Pokémon Go show that you can motivate kids to move if you apply the proper incentives.

It has been shown that even short bouts of physical activity, performed throughout the day, stimulate positive changes in cellular energy metabolism, growth, and development, and rather than making physical activity exclusive to the hour a day spent at the gym, we should be focusing on incorporating movement into all aspects of our life [17]. Concurrent with improvements in our exercise prescription, we should also attempt to trade sedentary activities like TV watching with active recreation like hiking, biking, swimming, playing games, playing music, and more.

In closing, our biology expects movement to be the rule and rest and relaxation to be the exception. Our modern world has allowed chronic sedentarism to take hold, and along with poor diets, stress, and other factors, we are seeing epidemic levels of cardiovascular disease, obesity, diabetes, and other diseases associated with the Western lifestyle pattern. However, movement provides an antidote to sedentarism and can reverse the metabolic and physiological changes brought about by spending too much time sitting still.

\section{References}

[1] D.W. Dunstan, E.L.M. Barr, G.N. Healy, J. Salmon, J.E. Shaw, B. Balkau, D.J. Magliano, A.J. Cameron, P.Z. Zimmet and N. Owen, Television Viewing Time and Mortality, Circulation, January 26, 2010, Volume 121, Issue 3.

http://circ.ahajournals.org/content/121/3/384

[2] American Time Use Survey Technical Note, Bureau of Labor and Statistics, 2014.

http://www.bls.gov/news.release/atus.tn.htm

[3] C. Dimitri, A. Effland, and N. Conklin, The 20th Century Transformation of U.S. Agriculture and Farm Policy, Economic Information Bulletin Number 3, June 2005.

http://www.ers.usda.gov/media/259572/eib3_1_.pdf 
[4] The Price of Inactivity, American Heart Association, Heart.org, October 2015.

http://www.heart.org/HEARTORG/HealthyLiving/PhysicalActivity/FitnessBasics/The-Price-ofInactivity_UCM_307974_Article.jsp\#.V-fDBPkrKM9

[5] T. S. Church, D. M. Thomas, C. Tudor-Locke, P. T. Katzmarzyk, C. P. Earnest, R. Q. Rodarte, C. K. Martin, S. N. Blair, and C. Bouchard, Trends over 5 Decades in U.S. Occupation-Related Physical Activity and Their Associations with Obesity, PLoS ONE, May 2011.

http://journals.plos.org/plosone/article?id=10.1371/journal.pone.0019657

[6] H. W. Kohl III, and H. D. Cook, Educating the Student Body: Taking Physical Activity and Physical Education to School, Institute of Medicine, 2013.

file:///C:/Users/Tony\%20FED/Downloads/18314.pdf

[7] C. Matthews, K. Y. Chen, P. S. Freedson, M. S. Buchowski, B. M. Beech, R. R. Pate, R. Pt. Troiano, Amount of Time Spent in Sedentary Behaviors in the United States, 2003-2004, Am. J.

Epidemiology, February 2008.

http://aje.oxfordjournals.org/content/167/7/875.long

[8] D.W. Dunstan, E.L.M. Barr, G.N. Healy, J. Salmon, J.E. Shaw, B. Balkau, D.J. Magliano, A.J. Cameron, P.Z. Zimmet and N. Owen, Television Viewing Time and Mortality: The Australian Diabetes, Obesity and Lifestyle Study, Circulation, January 2010.

http://circ.ahajournals.org/content/121/3/384

[9] D.W. Dunstan, E.L.M. Barr, G.N. Healy, J. Salmon, J.E. Shaw, B. Balkau, D.J. Magliano, A.J. Cameron, P.Z. Zimmet and N. Owen, Television Viewing Time and Mortality: The Australian Diabetes, Obesity and Lifestyle Study, Circulation, January 2010.

http://circ.ahajournals.org/content/121/3/384

[10] Y. Cho, S. Y. Park, J. H. Park, T. K. Kim, T. W. Jung, and H. M. Lee, The Effect of Standing and Different Sitting Positions on Lumbar Lordosis: Radiographic Study of 30 Healthy Volunteers, Asian Spine Journal, October 2015.

http://www.ncbi.nlm.nih.gov/pmc/articles/PMC4591449/

[11] Y. Cho, S. Y. Park, J. H. Park, T. K. Kim, T. W. Jung, and H. M. Lee, The Effect of Standing and Different Sitting Positions on Lumbar Lordosis: Radiographic Study of 30 Healthy Volunteers, Asian Spine Journal, October 2015.

http://www.ncbi.nlm.nih.gov/pmc/articles/PMC4591449/

[12] H. Petroski, To Chair Is Human: Lawn chairs, recliners, Aerons, strollers and an ancient Greek design that's never been beaten, WSJ.com, retrieved August 2016.

http://www.wsj.com/articles/to-chair-is-human-1472239096 
[14] H. Petroski, To Chair Is Human: Lawn chairs, recliners, Aerons, strollers and an ancient Greek design that's never been beaten, WSJ.com, retrieved August 2016.

http://www.wsj.com/articles/to-chair-is-human-1472239096

[13] Now I Sit Me Down: From Klismos to Plastic Chair: A Natural History By Witold Rybczynski, pg. 13, Farrar Strauss Giroux, 2016.

https://books.google.com/books?id=6nF_CwAAQBAJ\&pg=PA13\&lpg=PA13\&dq=chairs+reserved + for+nobility\&source=bl\&ots=TigsYQ2Sh\&sig=MWksf2npG2gwJtxQH0Nxa6Hn3m4\&hl=en\&sa=X\&ved=0ahUKEwjR4t787arPAhUHJ R4KHW1LD9IQ6AEIKTAE\#v=onepage \&q=chairs\%20reserved\%20for\%20nobility\&f=false

[15] A.M. Prentice, Early influences on human energy regulation: thrifty genotypes and thrifty phenotypes, Physiology and Behavior, December 2005.

http://www.ncbi.nlm.nih.gov/pubmed/16260008

[16] "You have been receiving signals of movement hunger in response to a movement diet that is very low in terms of quantity and poor in terms of quality-meaning you aren't getting the full spectrum of movement nutrition necessary for human function."

"Move Your DNA: Restore Your Health Through Natural Movement" by Katy Bowman, October 15th 2014, Propriometrics Press

[17] C. Latouche, J. B. M. Jowett, A. L. Carey, D. A. Bertovic, N. Owen, D. W. Dunstan, B. A. Kingwell, Effects of breaking up prolonged sitting on skeletal muscle gene expression, Journal of Applied Physiology, February 2013.

http://jap.physiology.org/content/114/4/453 